\title{
On the Centrality of Physical/Motor Activities in Primary Education
}

\author{
Evangelia Krevetzakis \\ Teacher of Physical Education, Crete, Greece \\ Doctoral Candidate, University of the Aegean \\ Email: evakrevetz@yahoo.gr
}

\begin{abstract}
The aim of this paper is to reclaim the value of movement/physical activity, and hence the value of physical education in the school curriculum. The paper discusses, on the one hand, the role of movement/physical activity in the context of learning, by citing the relevant research literature, and more specifically the benefits of including movement/physical activity in the school curriculum (e.g., improvement of students' short-term and long-term memory, stress reduction, invigoration of existing brain cells, growth of new neural connections, increase in focus and retention, regulation of students' energy), and, on the other hand, the role of the human body in the process of concept development and meaning making. The implications of this discussion for an integrated approach to the teaching and learning of physical education is also discussed, something that can be used as a justification of physical education as a school subject which can contribute to students' general education.
\end{abstract}

Keywords: Physical education, movement, sensorimotor experiences, embodied thinking, brainbased learning, curriculum integration.

\section{Introduction}

No doubt the development of thinking skills and the acquisition of curriculum content knowledge are important educational goals. But the questions regarding the design of learning sequences and activities that can best help with the achievement of these goals cannot be easily answered. Which organization, for example, of the curriculum, (e.g., around separate disciplines or around real-life issues and themes) is most appropriate for helping students develop thinking skills and learn effectively subject matter? Do student-centered or teacher-centered approaches work best when it comes to the development of such educational outcomes? The most reasonable answer to this kind of questions is that, depending upon the specific opportunities students have, thinking skills can be developed and content knowledge can be acquired regardless of the organization of the curriculum and regardless of the teaching-learning approach. This paper will attempt to make the case that physical/motor activity can provide students with opportunities for thinking and, hence, opportunities for learning the various schools disciplines. Even though the work of Piaget (1971) emphasized the importance of sensorimotor experiences in the early stages of cognitive development, recent empirical evidence suggests a bodily basis for thinking and its continuity beyond the sensorimotor stage or even well beyond early childhood (see Hannaford 2005; Seitz 2000).

Nowadays, with the abandonment of the mind/body dualism, and the attention that we have begun to pay to the idea of 'holistic experience' (Hadzigeorgiou, 2016; Hadzigeorgiou \& Schulz, 2014), the role of the human body in the processes of thinking and learning needs to be examined anew. Moreover, the notion of 'kinethesis' or 'kinesthesia' (i.e., the ability to perceive and feel movement) is an important one to consider when it comes to teaching and learning. Indeed, during the perception of bodily movement one is able to detect changes in body position without relying on sensori information (i.e., information from the five senses).Thus, in light of the notion of 'kinesthesis', even simple everyday activities, such as walking, running, and jumping acquire an educational significance that goes well beyond the subject of physical education. In this paper I will discuss the role of physical/motor activities in the learning process from a general perspective, including conceptual development, and I will then draw implications for the role of physical education in an integrated school curriculum. 


\section{The Role of Physical/Motor Experiences in the Learning Process}

Over the past two decades the idea that movement and thought are closely linked has been gaining attention by both researchers and educators. Neurophysiologist Hannaford's (2005) research has provided evidence for an intricate interplay among muscles, thought and emotions. The human brain is indeed activated during physical activity, and as Blakemore (2003) points out, such activity invigorates existing brain cells, and this may very well be the reason why movement improves learning outcomes.

According to a review study and meta-analysis by Watson et al. (2017), physical activity may provide a practical, low-cost, and effective strategy to increase academic-related outcomes, especially positive effects on improving on-task and reducing off-task classroom behaviour. Certainly, the findings from this review study should be interpreted with caution, given the low methodological quality of many studies that were included in the meta-analysis. Nonetheless physical activity is found to have positive effects on learning outcomes. The researchers, however, do stress the fact that it is not clear if improvements in learning outcomes are a result of the physical activity per se or simply a result of the break from academic instruction. Moreover, the studies that they reviewed did not differentiate the type of classroom-based physical activity (e.g., aerobic, anaerobic, resistance training, cognitively engaging physical activity, non-cognitively engaging physical activity). Nevertheless, the findings from brain studies point to a number of benefits, as was said before, of including movement/physical activity in the classroom.

From an educational perspective, brain-based learning seriously considers the role of movement in the learning process, in line with the ideas of humanistic education (Hadzigeorgiou, 2005). However, the benefits of movement go well beyond the 'humanistic context' in which movement can play a crucial role in fostering student learning. Increased oxygen to the brain can enhance students' ability to learn. Also structural changes in the central nervous system and alterations to neurotransmitters are also possible through movement. And it should be pointed out that, even though 'brain breaks' are important in the context of teaching and learning (e.g., taking breaks helps students to learn better as they return to their learning tasks energized and with renewed interest), movement in general, during the teaching-learning process helps improve students' both short-term and long-term memory, and also helps with stress reduction, and the growth of new neural connections. Movement helps increase focus and retention, and also helps children regulate their energy, thus leading to lower rates of behavioural problems and behaviour in general (e.g., bullying, fighting). Moreover, movement can help students understand abstract concepts by making them more tangible (see Clark, 1997, 1999; Cone, Werner, Cone, \& Woods, 1998; Dourish, 2001; Hadzigeorgiou, Anastasiou, Konsolas, \& Prevezanou, 2009; Kirkendall, 1985; Lakoff \& Johnson, 1999; Pellegrini \& Bohn, 2005; Ratey, 2002; Seitz, 1993; Thelen, Schoner, Scheier, \& Smith, 2001; Whitmer, 2014).

Harvard Medical School professor of psychiatry John Ratey (2002) points out that movement/physical activity optimizes attention and alertness, in addition to the contribution it makes to people's motivation and mental health. According to his research findings, in the case of students who learn to perform complex motor patterns, the formation of complex synaptic connections that take place in the brain help improve the students' brain's ability to process new information. Thus the brain responds to motor development just like muscles do, that is, growing with it and withering without (Ratey, 2002; Ratey \& Hagerman, 2008).

Hannaford's (2005) study with 5th grade special education students who participated in daily "Brain Gym" activities provided evidence that in one year 95\% of those students gained between two and one and a half years in reading ability. She also found that in a six-year longitudinal study $74 \%$ of special education students with reading disabilities (who were taught with traditional teaching methods) showed significant gains in reading ability.

What needs to be noted is that movement/physical activity is not just important, as Burton and VanHeest (2007) point out through their review study, because there is a link between movement and overweight and academic achievement in minority youth. Notwithstanding the importance of such finding, there are many studies which have documented the link between movement and improved learning as well (see Whitmer, 2014; Ratey, 2002). Young children can indeed show significant gains in establishing whole brain/body integration (i.e., neurological reorganization can take place in response to physical activity). All these studies provide evidence that we do not simply inhabit our bodies; we also 
think with them. The empirical evidence so far for the bodily basis of thinking and its continuity beyond the sensorimotor stage or even well beyond early childhood (e. g., Berluchi \& Aglioti, 1997; Epelboim, 1997; Hannaford, 2005; Ito, 1993; Seitz 2000; Wilson, 2001) is something that we should seriously consider. According to Jenson (2005), at a 1995 Annual Society of Neuroscience Conference, it was reported that approximately 80 studies found "strong links between the cerebellum and memory, spatial perception, language, attention, emotion, nonverbal cues, and even decision" (p. 85). Such findings do support the use of movement to activate and promote thinking.

It should be noted that Piaget's monism (i.e., the rejection of the Cartesian dualism, and hence the unification of mind and body) was the basis of his constructivist perspective, which "remains almost unique among other developmental theories" (Bidell \& Fischer, 1993, p. 102). But although Piaget recognized the central role of bodily experience in cognitive development, "the main thrust [of his theory] absorbed sensorimotor learning into higher systems of thought draining it of its cognitive uniqueness and centrality in early as well as later learning (Seitz, 2000, p. 24).

The work of Harvard professor of Human Cognition and Education Howard Gardner, on the other hand, did acknowledge that 'cognitive uniqueness' of sensorimotor learning. Indeed, Gardner's (1983, $1989,1993)$ theory of multiple intelligences has provided support for the idea that movement is an indispensable part of thinking and learning. Bodily-kinesthetic intelligence (i.e., one the eight intelligences in multiple intelligences theory) makes us rethink, not simply the nature of human intelligence, but, most importantly, how people in general, and young children in particular, think and learn in specific contexts.

It should be noted that the utilization of movement/physical activity in the context of teaching and learning is in line with constructivism (as both an epistemology and a theory of learning), which emphasizes the active role of the student and the attempt on his/her part to make sense of his/her experience (Stefanich \& Hadzigeorgiou, 2001). Specifically, the inclusion of themes (e.g., health, peace) makes the integration of movement through the subject of physical education a necessity, which though I will discuss in the section on the role of physical education in an integrated curricular context. Given though the centrality of movement in our making sense of the world, in the following section I choose to discuss the role of movement in the development of conceptual understanding.

What I should point out, however, in closing this section, is that despite lack of evidence on the socalled "learning-styles' approach to effective learning (i.e., matching the representation of knowledge during the teaching process with the learner's learning style, that is, auditory, visual, tactile, kinesthetic), according to research findings (e.g., Pashler, McDaniel Rohrer, \& Bjork, 2008; Rohrer \& Pashler, 2010, 2012), the idea that there are indeed many benefits resulting from the use of movement/physical activity in the classroom, and in the school curriculum, in general, cannot be disputed. Nor can it be disputed the idea of embodied thinking, which is discussed in the next section.

\section{Movement as the Basis of Conceptual Development}

From the perspective of conceptual development, just as action schemes (which form the basis of the Piagetian sensorimotor intelligence) are considered the precursors of concepts, children's early bodily experiences can be considered the basis upon which conceptual development will later take place. For example, very young children begin to develop first such intuitive concepts as work and energy through their experience with carrying toys up to their room (i.e., In the case of work they begin to recognize that carrying more weight to higher levels takes more work). It is evident that, as children grow up and gradually begin to recognize the scalar values for weight and height and also learn how to perform simple arithmetic operations, their concept of work can subsume new meanings (Hadzigeorgiou, Anastasiou, Konsolas, \& Prevezanou, 2009; see also Ausubel, Novak, \& Hanesian, 1978, for the role of children's physical activity in conceptual development from the perspective of Assimilation Theory).

Hadzigeorgiou's studies also provided evidence for the effect of sensorimotor activities on concept development. In a study that utilized a two-group design and investigated whether participation in sensorimotor activities by preschool children (involving their own bodily balance while walking on a beam over the floor) has an effect on their understanding of the mechanical equilibrium of a balance beam, it was found that children who participated in the sensorimotor activities could select, out of a number of objects, those two with the same weight regardless of their shape, size or colour, in order to 
balance the stick. In contrast, the children of the control group - which had previously participated in a hands-on activity regarding the equilibrium of a similar balance beam, and which (children), therefore, had a definite advantage over the other children who had participated in the sensorimotor activity - did not perform as successfully. A Chi Square Test showed no significant differences between the two groups on both an immediate and a delayed post-test, while the McNemar Test for the

Significance of Change showed a statistically significant difference (that is, a negative change in performance between the first and the second post-test) only within the hands-on group (Hadzigeorgiou et al., 2009).

The results of another two studies (Hadzigeorgiou, 2002; Hadzigeorgiou \& Savage, 2001), whose objective was to investigate whether sensorimotor experiences can help young students aged 9-10 years to construct a mental model involving a relationship between the speed of the molecules of a substance and its temperature, also showed significant gains regarding the construction of mental models. The sample in the first study (Hadzigeorgiou \& Savage, 2001) consisted of 86 children who were randomly assigned to two groups. The children of the experimental group participated in sensorimotor activities involving the children's movement (i.e., they pretended to be molecules moving around), while the children of the control group were presented with photographs and animated pictures regarding the motion of "little balls" - the molecules - in various contexts similar to those the children of the experimental group participated in (i.e., movement of molecules in solids, liquids and gases). The assessment of children's understanding was based upon six tasks involving visual material (photographs and animated pictures), and took place one week after the treatment and four weeks later. The results showed a significant difference (found through a t-test between the two groups on both occasions and through the correlation coefficients between the scores on the two tests for both groups). Similar results were reported by a second study with approximately the same number of students and the same ages. It was found that the experimental group of children (i.e., those who participated in the sensorimotor activities) did better in subsequent tests that assessed their understanding of the relationship between temperature and molecular motion, even though a statistically significant difference was found only in the delayed post-test.

Such findings are crucially important when it comes to designing activities. Indeed, the aforementioned three studies by Hadzigeorgiou and his colleagues do show that enactive representations of knowledge can be more effective, compared with iconic or symbolic ones (see Bruner, 1966, for the three different representations of knowledge), in certain contexts. In the two studies that investigated children's understanding of the relationship between molecular motion in solids, liquids and gases, enactive representation were more effective that iconic ones, and this has implications for curriculum and instruction, which I will discuss in the section on the integration of physical education with other school subjects, at least with science and mathematics.

The aforementioned results are in line with philosophical work the role of the human body in the process of meaning making and understanding. Indeed, the work of philosopher Mark Johnson makes us reconsider the view that it is only or mainly athletes and dancers that think through their bodies. The premise on which Johnson's (1987) book The body in the mind: The bodily basis of meaning, imagination and reason is based is that almost all of our knowledge derives from bodily experiences through metaphorical projections into abstract domains. According to him, bodily motion and forces are crucially important, not only at a preconceptual level; they are crucially important at every stage of cognitive development as they give meaning both to our physical experiences and to many abstract concepts of our language through the use of metaphors.

According to Johnson (1987), the most fundamental of all concepts are those of force and motion, which, through bodily experiences from the day we are born, develop into various mental models such as those of compulsion, blockage, contact, attraction, balance, equilibrium, in - out orientation, containment, trajectory, and so forth. In other words, physical/motor experiences provide the framework for structuring our concepts with which we interact with and understand the world. Johnson (1987) went as far as to argue that even emotions like anger, are represented through a mental model, which involves a fluid within a container that bursts open. And the concept of symmetry is developed not through our perceptual experiences with symmetrical objects but, instead, through our experiences of bodily balance.

Johnson (1987) uses the term "schema" instead of "mental model", and argues that schemas (or schemata) "fall between abstract propositional structures [. . .] and particular concrete images" (p.29). 
Although these schemas can also "constrain our meaning and understanding" (p.138), in the sense that that they give rise to certain misconceptions (e.g., the schema of 'force-in-the-direction-of-motion' constrains our scientific understanding of the concept of 'force'), they are nonetheless crucially important as they act as structures for organizing and understanding the world.

It is therefore evident that that we do not simply inhabit our body; we also think with it. As Lengel and Kuczala (2010) have noted, the human body is indeed an outward extension of the brain. Thus we need to acknowledge the fact that in every single movement of the human body and every physical activity, in general, movement and thought go hand in hand. From head scratching during thinking and communicating through body language to calculating with fingers, toes, and even with teeth, one can find many examples from everyday life where bodily movement and activity go hand in hand with thinking. And the fact that we use our bodies to understand abstract concepts (through the use of metaphorical projections) makes the bodily basis of thought quite apparent. However, although the Cartesian dualism has long been abandoned in most areas of philosophy and psychology (Damasio, 1996; Hadzigeorgiou, 2016; Lock \& Farquhar, 2007; Seitz, 1993, 2000), in everyday life and education our thinking is based on such a dualism (i.e., we tend to separate the body from the mind). It is beyond the scope of this paper to examine the persistent tendency for Cartesian dualism. However, it deserves to be pointed out that the education process may very well be the right - and perhaps the first - place where the abandonment of this dualism can begin to take place (i.e., through opportunities for students to think through their own bodies), thus helping students to become aware that the qualities they tend to associate with their mind cannot exist separate from their body.

\section{Physical Education in an Integrated Context}

As was already mentioned in the introduction, thinking skills and acquisition of subject matter are two crucially important goals. Given the role that movement/physical activity can play in the learning process, according to the research cited in the previous two sections, it is apparent that physical education can be an important subject that can make a contribution toward the achievement of these two goals. Indeed, in acknowledging the centrality of physical movement in the thinking process, one does not simply justify the inclusion of physical education in the school curriculum. For there are a number of goals (e.g., promotion of health and fitness, learning various skills) that can be achieved through physical movement in the context of schooling and education. One also acknowledges the crucial role of physical education to promote thinking in a variety of contexts, and hence contribute to learning outcomes, such as the acquisition of curriculum content knowledge.

Given the traditional teaching of physical education (i.e., as a separate discipline) does not contribute to the achievement of cognitive goals, an interdisciplinary approach can - and should - be seen as the main avenue for the achievement of such goals. Indeed, it has been found, through a review study, that, by and large, the cognitive and emotional objectives of physical education are left to chance (Kaittani, Derri, \& Kioumourtzoglou, 2016; see also Tishman \& Perkins, 1995). And it is precisely for this reason that physical education needs to be taught in interdisciplinary or even an integrated, in general, context (apart from the fact that such approaches can be really motivating for young students who are interested in certain topics, themes, issues or problems).

It is important here to point out that, according to Lengel and Kuczala (2010, p. ix), there are six purposes for incorporating movement in the classroom: (a) Preparing the Brain, (b) Providing Brain Breaks, (c) Supporting Exercise and Fitness, (d) Developing Class Cohesion, (e) Reviewing Content Using Movement, (f) Teaching New Content Using Movement. In light of the trend for interdisciplinary, multidisciplinary and integrated, in general, curricula (see Jacobs, 1989; Jones, 2009; Klein, 1996), movement can be incorporated across a wide variety of teaching sequences and curricular approaches, as it (movement) can foster the development of thinking skills and the acquisition of curricular content.

Interdisciplinary learning refers to the process whereby two or more disciplines are integrated with the goal of fostering enhanced learning in each of those disciplines (e.g., language arts-science, arts-science, physical education-science-geography, mathematics-science-social studies). The disciplines are related in some way (e.g., through a skill, a topic, a central theme, issue, or problem, a process (Jacobs, 1989). Language arts and science, for example, can be related through the skill of reading, while physical education and science (and even mathematics) are related through the topic or theme of the human 
body. It is evident that the implementation of an interdisciplinary approach to teaching presupposes collaborative work among the teachers of the various disciplines.

Even though there is a recognition of the value of interdisciplinary approach to teaching and learning, and therefore there is no point for teachers to discuss whether they should implement such an approach, there is nonetheless the issue of the degree to which they should implement it and how best to do it (Jacobs, 1989; Haynes, 2002; see also Harri et al., 2017). On the other hand, when one speaks, not of interdisciplinarity, but of curriculum integration, one indeed feels overwhelmed by the great number of ways in which one can integrate the curriculum (see Fogarty, 1991). The point though is that all these ways have one thing in common: the relationship, the connection between the disciplines. I prefer to talk about three integrated approaches, namely the interdisciplinary approach, the multidisciplinary approach, and the thematic/issues-based approach.

A review study by Kaittani, Derri,and Kioumourtzoglou (2016) found that most of research regarding interdisciplinarity was conducted with elementary school and preschool children, and all of them showed the positive impact of interdisciplinary programs on improving different skills, such as language, mathematical, and movement. Even though some studies have explored, as Kaittani et al. (2016) report, the benefits resulting from the interdisciplinary teaching of physics and physical education, more research needs to be done in order to determine the exact benefits of such an approach. Nonetheless, with regard to the concepts and principles of Newtonian mechanics (e.g., mass, inertia, momentum, angular momentum, moment of inertia, action and reaction, momentum), physical education can be used to illustrate such concepts and principles both in familiar everyday physical activities (e.g., walking, running) and sports movements (e.g., high jump, long jump, shot put, pole-vault).

It deserves to be stressed that, whether in an interdisciplinary context (i.e., physical education is taught with one or two school subjects for the purpose of enhancing learning in these subjects), in a multidisciplinary context (i.e., physical education is taught as a subject, along with all other subjects, for the purpose of contributing to students' understanding of a topic through the knowledge that each and every discipline can contribute) or in a thematic context (i.e., physical education makes a contribution, along with some other school subjects, to students' understanding of a topic, issue or problem, through their attempt to answer some questions relevant to the topic, issue or problem), the key issue that needs to borne in mind is integration. In fact, the recommendation that the physical and health education curriculum be the starting point for curriculum development (Popeska \& JovanovaMitkovska, 2016) is about the potential of physical education to integrate many disciplines, and is an idea worth considering in the context of curriculum development.

However, what should be also pointed out is that teaching physical education in an integrated approach, especially in a thematic/issues-based approach, is in line with a constructivist perspective. For there are excellent opportunities for students to reflect, to discuss in groups, to argue, to reorganize their ideas, and revise, if necessary, in order to understand the theme, topic, or issue under consideration (Stefanich \& Hadzigeorgiou, 2001). These opportunities, in turn, become opportunities for the achievement of significant educational goals (e.g., critical thinking, creative thinking).

Thus, we have to recognize that if physical education is to be considered a subject that can make a contribution to the achievement of significant educational goals (e.g., critical thinking, creative thinking), then it must be taught in a way that cognitive goals are achieved as well. Integrating physical education with other school disciplines can be an effective way to give physical education teachers the opportunity to contribute to the achievement of cognitive goals. For it is quite apparent that in formal physical education programs, physical education is taught as a subject that will help students to develop certain motor skills, be competent in sports activities, and also develop physical fitness and endurance. Even though the achievement of these goals presupposes or helps foster both cognitive goals (e.g., one has to think how to apply certain rules) and emotional goals (e.g., one becomes highly satisfied when successfully executes a motor skill, or wins in a team game), the teaching emphasis is placed on psychomotor goals (see Kaittani et al. 2016). Such emphasis, apparently, cannot contribute to students critical thinking skills, when it comes to the relationship between such notions as "physical culture" and "identity" and exercise/physical activity (see Sandford \& Rich, 2006). In contrast, integrating physical education with other subject matter areas can be more effective in helping students to think critically about these notions and thus develop a critical consciousness, in line with a critical pedagogy perspective (see Devis-Devis, 2006), and also a purpose for learning (Hadzigeorgiou, 2001). 
However, what also needs to be recognized is that teaching physical education in an integrated context can be in line with the ideas of holistic education too (depending on the degree of integration, that is, form a simple connection of two or more subject matter areas to a thematic approach, in which the boundaries between these areas become blurred). Indeed, an integrated approach can provide ample opportunities for the education of the whole person, by involving body, mind and spirit, and for developing in students an awareness that all things are interconnected and related in some way, including their own self (Hadzigeorgiou, 2005).

\section{Concluding Comments}

In this paper I attempted to point out the crucial role of movement/physical activity in the learning process and how physical education, as a school subject, can make a contribution to the achievement of cognitive goals too. Even though the brain and the body have been separated for both medical and educational purposes, movement proves to be an "efficient way for students to learn and remember content" (Lengley \& Kuczala, 2010, p. 8). Ratey's (2000) view that movement is the "miracle grow" for the brain should not be considered an exaggeration, for it contains an element of truth, especially in the context of early childhood education: movement can benefit children from a variety of perspectives, as was discussed in this paper. We may talk about hands-on learning, about "manipulating ideas", about body language conveyed through gestures and posture, even through facial expressions, in order to show the connection between the body and the mind. But the discussion in this paper made it quite clear that we literally think with our bodies, as the research program of "embodied cognition" shows (Hadzigeorgiou et al., 2009; Thelen et al., 2001; Varela et al., 1991). And the motto "I move, therefore am I" (Seitz, 1993) should be a reminder, not just of the Cartesian fallacy, but of the centrality of movement/physical activity across the school curriculum, especially the primary school curriculum. For it is crucial to point out that, although physical education is important students of all ages, such benefits as the development of self-regulation, self-esteem, and self-confidence - in addition to the promotion of health and fitness and the development of motor and cognitive skills - make its role is quite crucial in primary education, which can lay the foundations for subsequent development and learning.

If scholars from the fields of social science and humanities - as Lock and Farquhar's (2007) co-edited book Beyond the Body Proper shows - have moved beyond the idea that there is iust a "body proper", that is, a singular biological organism (and therefore there are social and anthropological implications), then physical education should move beyond its supposed psychomotor emphasis - through both the explicit and the taught curriculum and, of course, the hidden curriculum - and become much more encompassing, and, as such, the connecting ring with other subject matter areas. Thus it can contribute to students' general education (and in this sense it can be considered a school discipline that makes indeed a contribution to a liberal education) and its inclusion in the school curriculum be totally justified (see Hadzigeorgiou, 2017; Hadzigeorgiou \& Stamatis, 2017).

But, perhaps, most importantly, physical education can be justified as a disciplinary area that has value, not simply because it can make a contribution to students' health and fitness - even a significant one - but because there are values inherent to the subject matter of physical education itself (Kretschmann, 2018; see also McNamee, 1998), which are difficult - perhaps very difficult - to cultivate through the teaching of other school disciplines. Self-confidence, personal and social responsibility, tolerance, unity and teamwork, moral and ethical behaviour are values that can be cultivated more effectively in an integrated context (which can also include project-based work), which helps students to become aware that these are human values in all areas of human endeavour and experience, and that participation in physical education is indeed a worthwhile educational activity that transcends the development of the psychomotor domain.

\section{References}

1. Ausubel, D., Novak, J., \& Hanesian, J. (1978). Educational psychology: A cognitive view. New York: Holt, Rinehart \& Wilson. 
2. Berlucchi, G., \& Aglioti, S. (1997). The body in the brain: Neural bases of corporeal awareness. Trends in Neurosciences, 20, 560-564.

3. Bidell, T., \& Fischer, K. (1993). Beyond the stage debate. In R. Sternberg, \& C. Berg (Eds.) Intellectual development (pp. 98-142). Cambridge, MA: Cambridge University Press.

4. Blakemore, C. (2013). Movement is essential to learning. Journal of Physical Education, Recreation \& Dance, $74(9), 22-25$.

5. Bruner, J. (1966). Toward a theory of instruction. Cambridge, MA: Harvard University Press.

6. Burton, L., \&. VanHeest, J. ( 2007). The importance of physical activity in closing the achievement gap. Quest, 59, 212-218.

7. Clark, A. (1997). Being there: Putting brain, body, and world together again. Cambridge, MA: MIT Press.

8. Clark, A. (1999). Embodied, situated, and distributed cognition. In W. Bechtel, \& G. Graham (Eds.) A companion to cognitive sciences (pp. 506-517). Malden, MA: Blackwell.

9. Cone, P., Werner, P., Cone, L., \& Woods, A. (1998). Interdisciplinary teaching through physical education. Champaign, IL: Human Kinetics.

10. Devis-Devis, J. (2006). Socially critical research perspectives in physical education. In D. Kirk, D. Macdonald, \& M. O'Sullivan (Eds.), The handbook of physical education (pp. 37-58). Thousand Oaks, CA: Sage.

11. Dourish, P. (2001). Where the action is: The foundations of embodied interaction. Cambridge, MA: MIT Press.

12. Damasio, A. (1996). Descartes' error: Emotion, reason and the human brain. London: Papermac.

13. Egan, K. (1997). The educated mind: How cognitive tools shape our understanding. Chicago: University of Chicago Press.

14. Epelboim, J. (1997). Deictic codes, embodiment of cognition, and the real world. Behavioral and Brain Sciences, 20,746 .

15. Fielden, S. (1995). The magical kingdom of movement. Hawaii: Edu Kinesthetics. future benefits of interdisciplinary studies. ESSAI, 7(1), p.26.

16. Fogarty, R. (1991). The mindful school: How to integrate the curricula. Iri/Skylight Training \& Publishing.

17. Gardner, H. (1983). Frames of mind: The theory of multiple intelligences. New York: Basic Books.

18. Gardner, H. (1993). Multiple intelligences. The theory in practice. New York: Basic Books.

19. Gardner, H. (1997). Extraordinary minds: Portraits of four exceptional minds and the extraordinary minds in all of us. New York: HarperCollins.

20. Glenberg, A. (1999). Why mental models must be embodied. In G. Rickheit \& C. Habel (Eds.), Mental models in discourse processing and reasoning (pp. 77-90). New York: Elsevier.

21. Golden, H. ( 2013). Integrating academics with physical education: how can it realistically be done? VAHPERD Journal, 34(2), 12-15.

22. Hadzigeorgiou, Y. (1997). Relationships, meaning, and the science curriculum. Curriculum and Teaching, 12 (2), 83-89.

23. Hadzigeorgiou, Y. (2001). Some thoughts on the notion of purposeful learning. The Educational Forum, 65 (4), 316-325.

24. Hadzigeorgiou, Y. (2002). The utilization of sensorimotor experiences for introducing young children to molecular motion: A report of a pilot study. Physics Education, 37, 239-244.

25. Hadzigeorgiou, Y. (2005). On humanistic science education. ERIC DOCUMENT (ED506504).

26. Hadzigeorgiou, Y. (2015). Imagination and learning science. In R. Gunstone (Ed.), Encyclopedia of science education, $480-483$.

27. Hadzigeorgiou, Y. (2016). Imaginative science education: The central role of imagination in science education. Cham, Switzerland: Springer.

28. Hadzigeorgiou, Y. (2017). Implications of R.S. Peters notion of 'cognitive perspective' for science education. Educational Philosophy and Theory, 49 (10), 1016-1028.

29. Hadzigeorgiou, Y., \& Savage, M. (2001). A study of the effect of sensorimotor experiences on the retention and application of two fundamental physics ideas. Journal of Elementary Science Education, 13(2), 9-21.

30. Hadzigeorgiou, Y., \& Fotinos, N. (2007). Imaginative thinking and the learning of science. Science Education Review 6 (1), 15-23.

31. Hadzigeorgiou, Y., Anastasiou, L., Konsolas, M. \& Prevezanou, B. (2009). A study of the effect of preschool children's participation in sensorimotor activities on their understanding of the equilibrium of a balance beam. Research in Science Education, 39, 39-55.

32. Hadzigeorgiou, Y. \& Schulz, R. (2014). Romanticism and romantic science: Their contribution to science education. Science \& Education, 23(10), 1963-2006. 
33. Hadzigeorgiou, Y., \& Stamatis, P. (2017). How relevant is R.S. Peters concept of education to science education? Interchange, 48(1), 1-18.

34. Hannaford, C. (2005). Smart moves: Why learning is not all in your head. Great Rivers Books.

35. Harri, R., Marttinen,J. McLoughlin,G., Fredrick III, R., \& Novak, D. (2017). Integration and Physical Education: A Review of Research. Quest, 69, 37-49.

36. Haynes, C. (Ed.) (2002). Innovations in interdisciplinary teaching. Westport, CT: Oryx.

37. Ito, M. (1993). Movement and thought: identical control mechanisms by the cerebellum. Trends in the Neurosciences, 16, 448-450.

38. Jacobs, H. (1989). Interdisciplinary curriculum: Design and implementation. Association for Supervision and Curriculum Development, 1250 N. Pitt Street, Alexandria, VA 22314.

39. Jensen, E. (2005). Teaching with the brain in mind. Alexandria, VA: Association for Supervision and Curriculum.

40. Johnson, M. (1987). The body in the mind: The bodily basis of meaning, imagination, and reason. Chicago: University of Chicago Press.

41. Jones, C. (2009). Interdisciplinary approach - Advantages, disadvantages, and the future benefits of interdisciplinary studies," ESSAI: Vol. 7, Article 26. Available at: http://dc.cod.edu/essai/vol7/iss1/26

42. Kaittani, D., Derri, V., \& Kioumourtzoglou, E. (2016). Interdisciplinary learning in education. A focus on physics and physical education. Sport Science 9, 22-28.

43. Kirkendall, D. R. (1985). Effects of physical activity on intellectual development and academic performance. Washington, DC: American Academy of Physical Education.

44. Klein, J. (1996). Crossing boundaries: knowledge, disciplinarities and interdisciplinarities. Charlottesville: University Press of Virginia.

45. Kretschmann R. (2018) Values and value education in physical education. In A. Schneider, J., Köhler, \& F. Schumann (Eds.) Fairplay im sport. Angewandte Forschung im Sport (pp. 69-82). Wiesbaden: Springer.

46. Lakoff, G., \& Johnson, M. (1999). Philosophy in the flesh: The embodied mind and its challenge to western thought. New York: Basic Books.

47. Lengel, T., \& Kuczala, M. (Eds.) (2010). The kinesthetic classroom Teaching and through movement. Thousand Oaks, CA Corwin Press.

48. Lock, M., \& Farquhar, J. (Eds.) (2007). Beyond the body proper. Reading the anthropology of material life. Durham, NC: Duke University Press.

49. McNamee, M. (1998). Education, philosophy and physical education: analysis, epistemology and axiology. European Physical Education Review, 4 (1): 75-91.

50. Mak, B., \& Vera, A. (1999). The role of motion in children's categorization of objects. Cognition, 7, 11-21.

51. Markman, A., \& Dietrich, E. (2000). In defense of representation. Cognitive Psychology, 40, 138-171.

52. Pashler, H., McDaniel, M., Rohrer, D., \& Bjork, R. (2008). Learning styles: Concepts and evidence. Psychological Science in the Public Interest, 9, 105-119.

53. Pellegrini, A., \& Bohn, C. (2005). The role of recess in children's cognitive performance and school adjustment. Research News \& Comments, January/February 2005. Available on line: http://www.creativitypost.com/ education/the_benefits_of_movement_in_schools\#_ftn3.

54. Piaget, J. (1971). Genetic epistemology. New York: Norton.

55. Popeska, B., \& Jovanova-Mitkovska, S. (2016). Integration and correlation concepts in physical education. Research in Kinesiology, 44, 262-269.

56. Port, R., \& van Gelder, T. (1995). Mind as motion. Explorations in the dynamics of cognition. Cambridge, MA: MIT Press.

57. Ratey, J. (2002). User's guide to the brain. Perception, attention, and the four theatres of the brain. Vintage.

58. Ratey, J., \& Hagerman, E. (2008). Spark: The revolutionary new science of exercise and the brain. New York: Little, Brown and Co.59. Rohrer, D., \& Pashler, H. (2010). Recent research on human learning challenges conventional instructional strategies. Educational Researcher, 39, 406-412.

60. Rohrer, D., \& Pashler, H. (2012). Learning styles: Where's the evidence? Medical Education, 46, 634-635.

61. Rovegno, I., \& Dolly, J. (2006). Constructivist perspectives on learning. In D. Kirk, D. Macdonald, \& M. O'Sullivan (Eds.), The handbook of physical education (pp. 242-261). Thousand Oaks, CA: Sage.

62. Sandford, R., \& Rich, E. (2006). Learners and popular culture. In D. Kirk, D. Macdonald, \& M. O'Sullivan (Eds.), The handbook of physical education (pp. 275-291). Thousand Oaks, CA: Sage.

63. Seitz, J. (1993). I move.... therefore I am. Psychology Today, 26, 50-55.

64. Seitz, J. (2000). The bodily basis of thought. New ideas in Psychology, 18, 23-40. 
65. Stefanich, G., \& Hadzigeorgiou, Y. (2001). Models and applications. In G. Stefanich (Ed.), Science teaching in inclusive classrooms (pp. 61-90). Cedar Falls, IA: Woolverton.

66. Tishman, S., \& Perkins, D.N. (1995). Critical thinking in physical education. Journal of Physical Education, Recreation and Dance, 66(6):24-30.

67. Thelen, E., Schoner, G., Scheier, C., \& Smith, L. B. (2001). The dynamics of embodiment: A field theory of preservative reaching. Behavioral and Brain Sciences, 24, 1-34.

68. Varela, F., Thompson, E., \& Rosch, E. (1991). The embodied mind. Cambridge, MA: MIT Press.

69. Watson, A., , Timperio, A., Brown, H., , Best, K., \&, and Hesketh, K. (2017). Effect of classroom-based physical activity interventions on academic and physical activity outcomes: a systematic review and metaanalysis. International Journal of Behavioural Nutrition \& Physical Activity, 14, 114. https://doi.org/ $10.1186 / \mathrm{s} 12966-017-0569-9$

70. Whitmer, R. (2014). Instruction in motion brings PE into classroom. Available on line: https://www. districtadministration.com/article/instruction-motion-brings-pe-classroom

71. Wilson, M. (2001). The case for sensorimotor coding in working memory. Psychonomic Bulletin and Review, 8, $44-57$. 